\title{
From the Unimate to the Delta robot: the early decades of Industrial Robotics
}

\author{
A. Gasparetto and L. Scalera \\ Polytechnic Department of Engineering and Architecture - University of Udine, \\ Udine, Italy, e-mail: alessandro.gasparetto@uniud.it / \\ scalera.lorenzo@spes.uniud.it
}

\begin{abstract}
In this paper, the early decades of the history of industrial robots (from the 1950's to the beginning of the 1990's, approximately) will be described. The history of industrial robotics can be considered starting with Unimate, the first industrial robot designed and built by Devol and Engelberger. The subsequent evolutions of industrial robotics are described in the manuscript, taking into account both the technical and the economic point of view, until the beginning of the 1990's, when new kinematic structures (parallel robots) appeared, allowing high-speed operations.
\end{abstract}

Key words: Industrial robots, history, Unimate, Stanford Arm, Delta robot

\section{Introduction}

Since ancient times, the humanity conceived the idea to design and to build some kind of beings, or devices, which could substitute men in heavy or repetitive work. Such beings, called automata, date back to the Greek-Hellenistic age and have been conceived by several civilizations throughout the centuries. A historical perspective of Robotics may be found in [1] and [2], while a brief history of automata and robots, from ancient times up to the Industrial Revolution, can be found in [3]. From the Industrial Revolution on, some forms of automatization took place in the industrial environment; however, it is only in the 1950's that what is known as "industrial robotics" started.

A chronological categorization of industrial robots has been proposed in terms of "generations" [4]. Four generations have been proposed, namely: first generation (1950-1967), second generation (1968-1977), third generation (1978-1999), fourth generation (from 2000 on).

The industrial robots of first generation are defined as programmable machines without the possibility of controlling the real modes of execution and without communication with the external environment. The robots of the first generation 
use low-tech equipment and did not employ servo-controllers. They are characterized by the strong noise made by their arms when colliding with the mechanical stops used to limit their movements. Almost all the robots of the first generation are pneumatic and their automatic regulators generally consist of air-actuated logic gates, implemented by means of drums that divide segments from cams that are used to activate pneumatic valves, or relays that control solenoid pneumatic valves. The first generation of robots of the sixties is essentially used for loading/unloading purposes or for carrying out simple material handling operations.

The second generation of industrial robots consists of programmable machines with self-adaptive behavior with elementary possibilities of recognition of the external environment. Such robots are equipped with servo-controllers, which can be programmed to move from point to point or along a continuous path. Their controller is based on programmable logic controllers (PLC) or minicomputers. A teach-box allows the users to online program the robot motion. The second generation of industrial robots is able to perform more complex tasks, with respect to the first one, such as the control of the work centers. Each robot is provided with dedicated software for a specific application: hence, it is rather difficult to use the same robot for a different task, because to do so, it would be necessary to substantially modify the control system and the operating software. Furthermore, the second generation robots has low diagnostic capabilities, which are generally limited to report failures to the operator by means of indicator lights. It is up to the operator to trace the actual causes of the failure.

The third generation robots are self-programmable machines interacting with the external environment and the operator in a more complex way (vision, voice, etc.), with some (limited) capability to reprogram themselves for the execution of an assigned task. The third-generation robots are machines that operated under servo control and can be programmed to move from point to point or along continuous paths. Scheduling could take place online by means of a prehensile keyboard or off line through a video display. This type of robot uses high-level programming languages and can be interfaced with a CAD database or with a host computer for the loading/unloading of programs. The available control systems can process sensory data to adjust the movements and compensate for changes in position and orientation of parts. Furthermore, thanks to the feedback of sensory data and the interfacing with a CAD database or a host computer, the third generation robots can send messages to the operator, to describe the nature and location of any failure. The third generation robots evolved to the point of being able to perform some sort of "intelligent" tasks, such as adaptive arc welding (during which the robot uses vision or perception "through the arc" to locate the welding joint and get information to guide the movement), or other complex tasks such as tactile inspections, freehand machining and assembly operations.

In the fourth generation, the "intelligent" capabilities of the robots reach a high level (advanced computing capabilities, logical reasoning and learning, complex control strategies, collaborative behavior). This generation extends up to the current days. 
In this paper, the focus will be set on the history of industrial robots in the $\mathrm{XX}$ century, in particular from Unimate (1959), the world's first industrial robot, to the Delta robot (1992), the first parallel robot installed in the industry.

It should be mentioned that very few papers about the history of industrial robots are present in the literature. Sketches of history of industrial robotics appear in some internal reports (such as [5] and [6]), as well as in some robotics books (as for instance in [2], [7], [8] and [9]).

\section{The dawn of industrial robotics: Devon, Engelberger and the Unimate robot}

Before dealing with the history of industrial robots, some important developments in automatization, which happened before the appearance of the first industrial robot, should be mentioned.

In 1938, Willard Pollard and Harold Roselund built the first "programmable" mechanism, namely a paint-sprayer for the DeVilbiss company.

In 1952 the first NC machine was developed at MIT in Boston by John Parsons and Frank Stulen, who filed a patent on "Motor Controlled Apparatus for Positioning Machine Tool". Such a machine was a milling machine numerically programmable for short series: it was a technical breakthrough in the automation scenario. The patent for this machine was granted in 1958 [10].

In 1949 Raymond Goertz filed a patent for a tele-operated articulated arm on behalf of the Atomic Energy Commission. This arm is considered an early version of master-slave manipulators. The patent for this device, named "Remote-control manipulator", was granted in 1953 [11].

The real start of the history of industrial robots is set in 1954, when John Devol, an American scientist, filed a patent for a "programmable article transfer" (patent granted in 1963) [12]. The method described in this patent was the key to the development of Unimate, the world's first industrial robot.

In 1956, during a cocktail party in Connecticut, Devol met Joseph Engelberger, a space-industry engineer. They discussed about the possible use of the machine patented by Devol, and conceived the idea to set up a company to design and build manipulators to be employed in the industry. In the following years, Devol and Engelberger visited many factories (mainly in the automotive sector), to better understand the needs of the production plants. In 1961, they founded the company Unimaton, which manufactured what is considered the first industrial robot, namely a hydraulically actuated manipulator called Unimate (Fig. 1), In the same year, the first Unimate was installed in the General Motors factory located in Trenton (USA): it could perform a single task, namely extracting parts from a die-casting machine. Further versions of Unimate were employed, in the following years, for workpiece handling and for spot-welding of car bodies. 


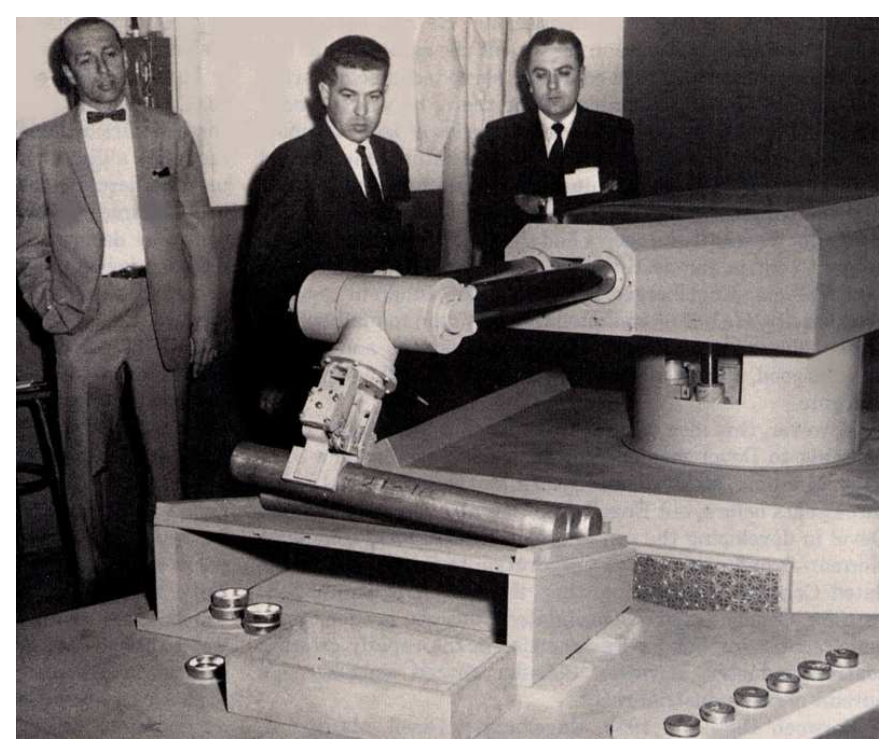

Fig. 1 George Devol and the Unimate [13]

In the meanwhile, several other entrepreneurs understood the potential of these new devices, and many companies that manufactured manipulators were created. The automotive companies (especially General Motors and Ford) launched plans to "automatize" their production plants, and placed big orders of manipulators, thus giving a boost to the robotic industry.

AMF Corporation developed in 1962 an industrial robot with a cylindrical coordinate frame, named Versatran (from the words "versatile transfer"), which was installed at the Ford factory located in Canton (USA). This robot (Fig. 2) was the first one imported in Japan in 1967; two years later, the company Kawasaki Heavy Industries Ltd. obtained from Unimation the license to build robots: this fact definitely gave a boost to the diffusion of robots in Japan. 


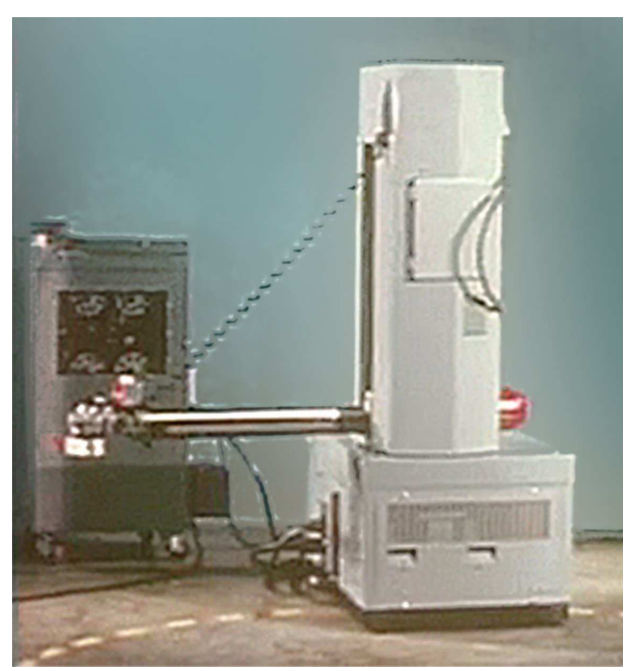

Fig. 2 Versatran (from [14])

The first robots in Europe were installed in 1967 at Svenska Metallverken in Upplands Väsby (Sweden): their tasks were simple and repetitive pick-and-place movements. In 1969, the Norwegian company Tralffa developed the first painting robot, which was employed in the painting of wheelbarrows.

The first welding robots were produced by Unimation, and installed at the General Motors assembly plants in Lordstown (USA) in 1969, to perform spotwelding to car bodies. In Europe, the first welding robots appeared at FIAT plants in Turin (Italy) in 1972.

\section{From hydraulic to electric robots: Scheinman, the Stanford Arm and the PUMA robot}

A breakthrough milestone in the history of industrial robots is the Stanford Arm (Fig. 3) built in 1969 by Victor Scheinman [15], a mechanical engineering student working in the Stanford Artificial Intelligence Laboratory (SAIL). It was the first all-electric manipulator, controlled by a microprocessor (PDP-6). It had six degrees-of-freedom ( 5 revolute joints and a prismatic joint): such a configuration allowed to quickly solve the inverse kinematics in a closed form, thus speeding up the computations required to the microprocessor. The robot actuators were six DC electric motors, and the kinematic chain was composed of harmonic drives and spur gear reducers. The manipulator was also provided with sensors, namely po- 
tentiometers and tachometers for measuring position and velocity, for controlling purposes.

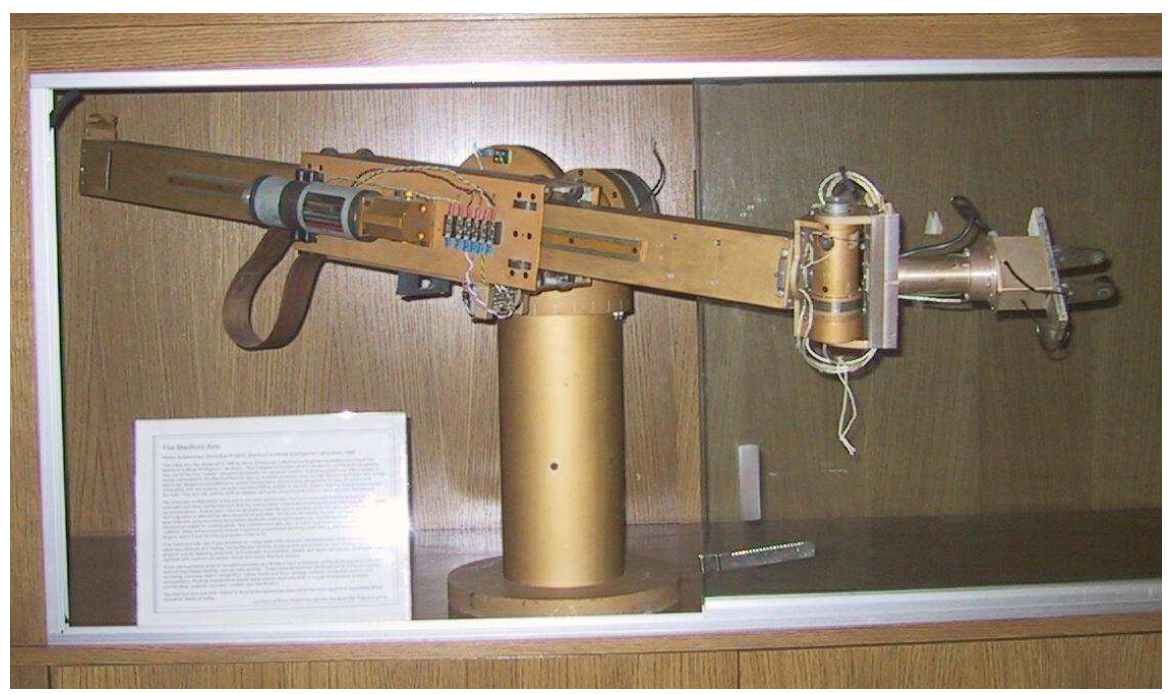

Fig. 3 Stanford Arm (from [16])

In 1973 Scheinman founded a company (Vicarm Inc.) to produce Vicarm, an electric robot intended for assembly operation. The idea was to build a manipulator smaller and lighter than Unimate, which could be employed for operations where it was not required to lift heavy loads. Vicarm was the first conception of electric robot: years later, the company founded by Scheinman was bought by Unimation and Vicarm was the basis for the development of the PUMA robot.

Scheinman's concepts greatly influenced the subsequent development of industrial robotics. Besides that, the results of the research and the development of the 1960 's were ready to appear in commercial products in the middle of the 1970's. In particular, the new microelectronic components, and especially the microprocessors, reached the technical maturity and could be used as a basis for costeffective and powerful control systems, which could be applied to computationally expensive tasks such as robot control. Furthermore, even economic and geopolitical events gave a boost to the automatization of industrial production: the oil crisis of October 1973 forced many companies to look for more efficient ways of production, and introducing robots in the production plants could serve this aim very well. For all these reasons, in the second half of the 1970's, the sales of industrial robots grew very rapidly, with a yearly increase of more than $30 \%$ in the average. [17]. 
In 1973 KUKA developed Famulus, the first robot to have six electromechanically driven axes. A year later (1974), the first microcomputer-controlled robot was introduced by Cincinnati Milacron, the biggest machine-tool manufacturer in the world. It was named T3 ("The Tomorrow Tool", Fig. 4), and was sold to several companies, especially of the automotive sector (Volvo in particular). In 1990 ABB bought the robotic division of Cincinnati Milacron [9].

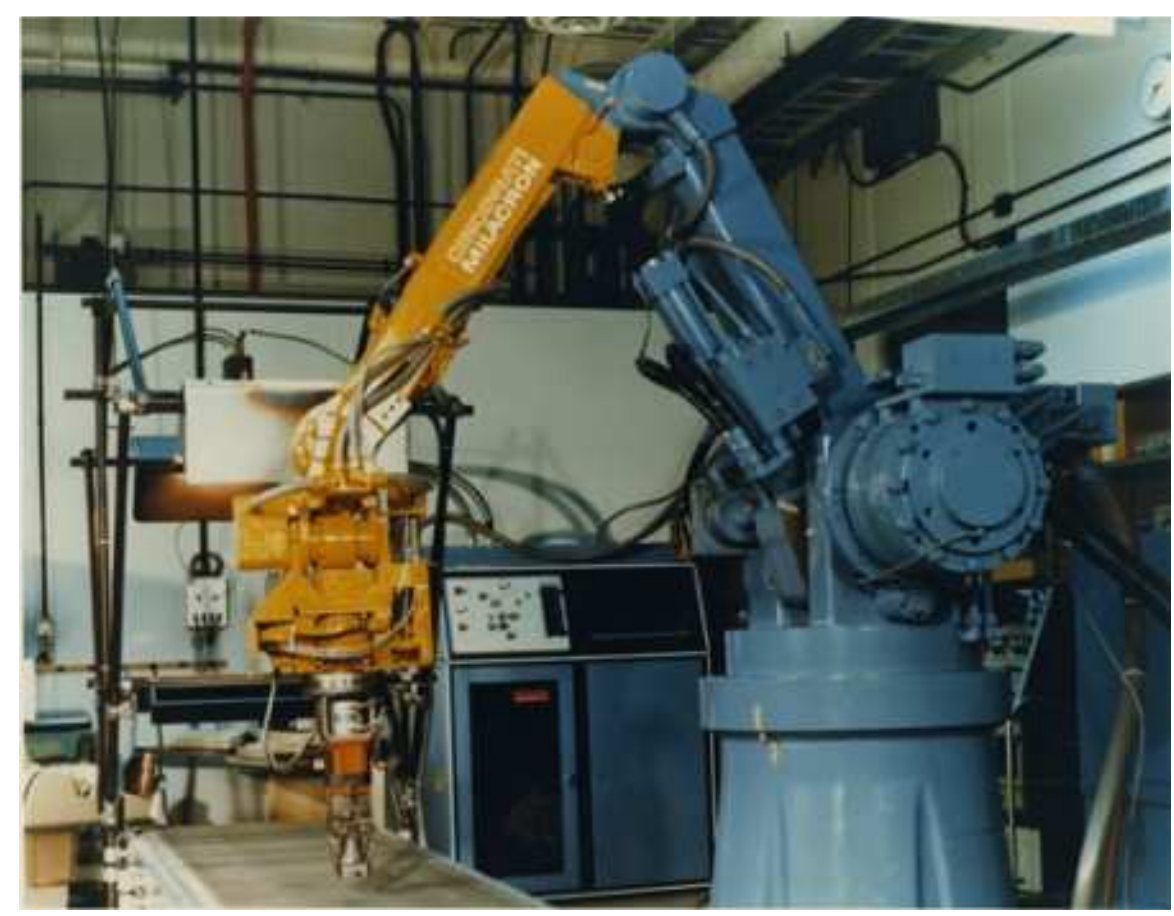

Fig. 4 The Cincinnati Milacron T3 robot (from [18])

In the same year (1974), ASEA (now ABB) developed the first all-electric industrial robot, controlled by a microprocessor. It was named IRB-6 (Fig. 5) and was able to perform continuous paths: for this reason, it was widely employed in the factories for tasks such as arc-welding or machining. The robots of the IRB series (characterized by their typical orange color) had a great success, and the production continued for more than 20 years. 


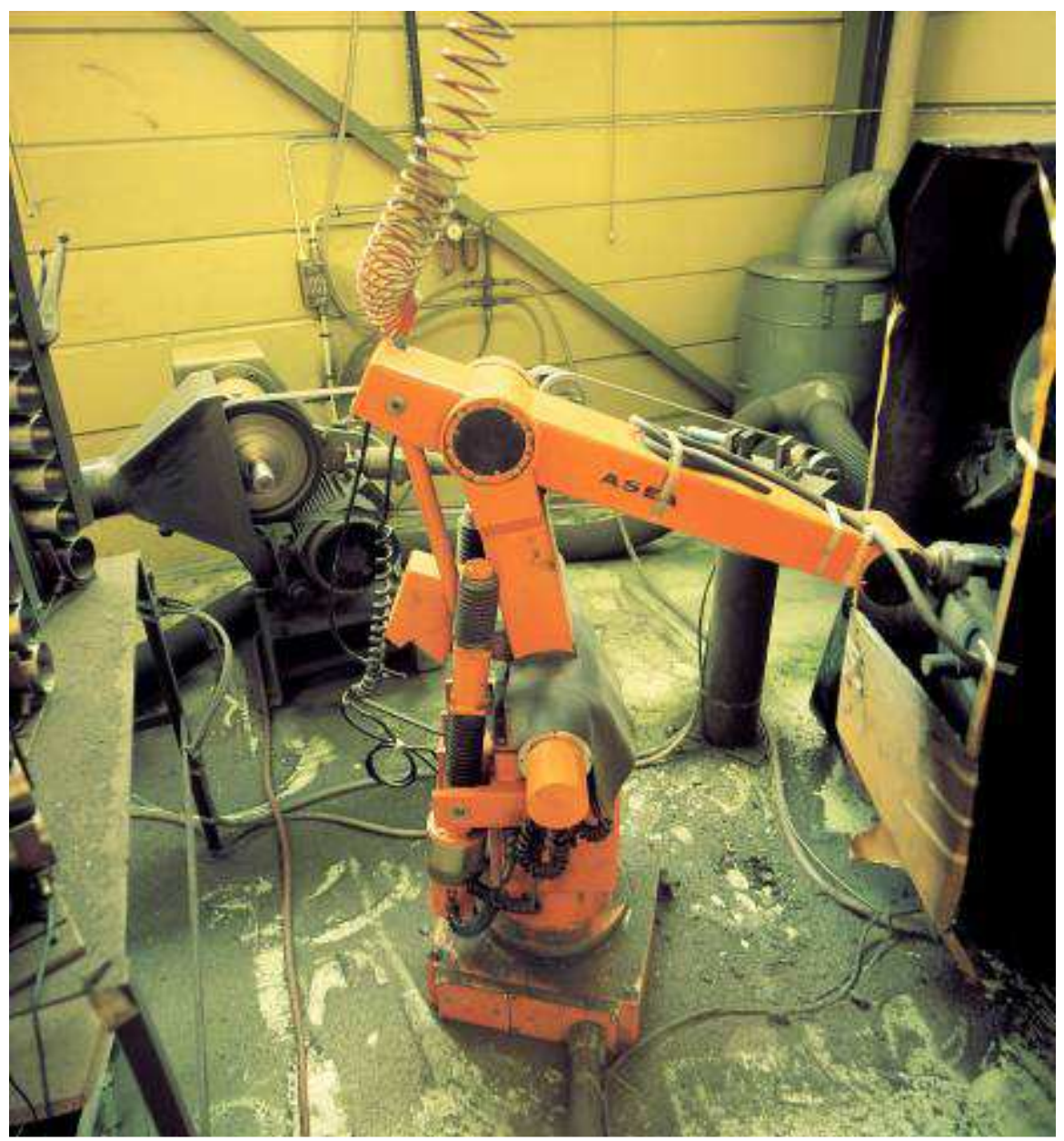

Fig. 5 The "legendary" IRB-6 (from [12])

In 1978, Unimation released, together with General Motors, a novel anthropomorphic robot named PUMA (an acronym for Programmable Universal Machine for Assembly). PUMA (Fig. 6) was considered archetypal for the anthropomorphic robots, and its kinematics was taken as an example in several robotics books in the academy worldwide. 


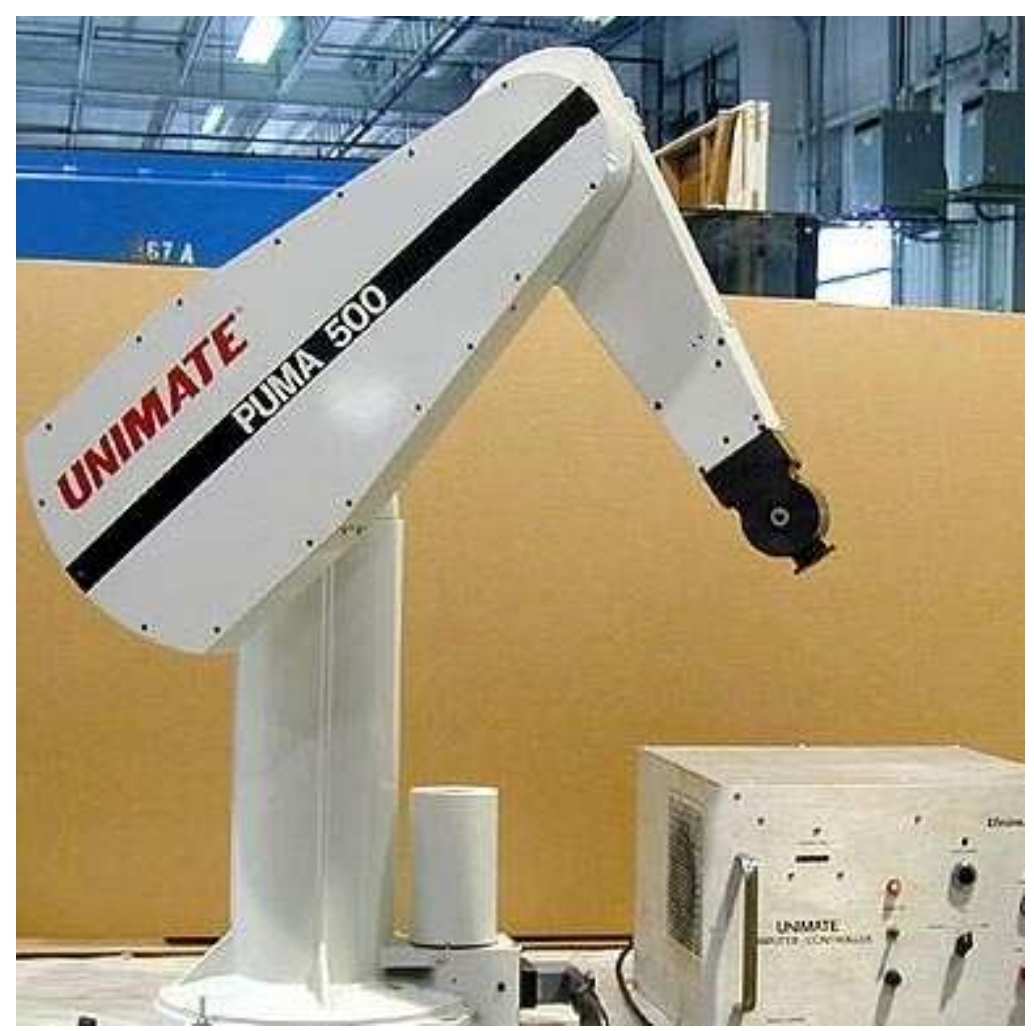

Fig. 6 The PUMA robot (from [16])

\section{The robotic boom of the 1980's}

In the same year (1978), another important milestone in the history of industrial robots came, when Hiroshi Makino of Yamanashi University (Japan) invented the SCARA robot (Fig. 7). Such a manipulator, named after the acronym "Selective Compliance Assembly Robot Arm", had an innovative kinematics and was perfectly suited for assembly of small parts. The simplicity of the kinematic chain made the control easy and very fast; moreover, the cost was considerably low, compared to other types of manipulators. The diffusion of SCARA robots gave a boost to the production of electronic consumer goods, which were assembled by this type of robots. This made the Japanese robotics industry lead the robotics industry worldwide: indeed, in 1980 Japan became the world's largest robot manu- 
facturer. By the end of the decade, Japan had about 40 robot manufacturers that dominated the global robot market.

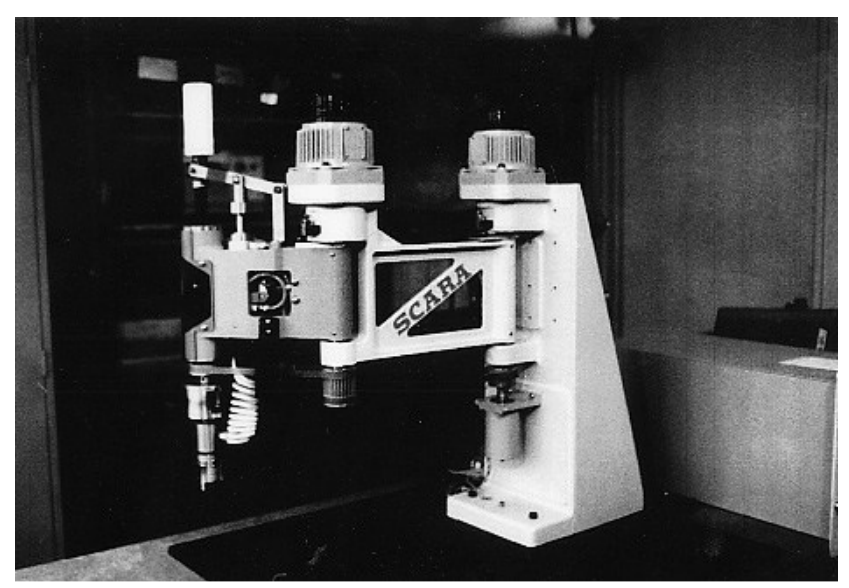

Fig. 7 The first prototype of SCARA robot (from [19])

In 1981 Asada and Kanade build the first direct-drive arm at Carnegie Mellon University (Fig. 8). It was named the CMU Direct Drive Arm [20].

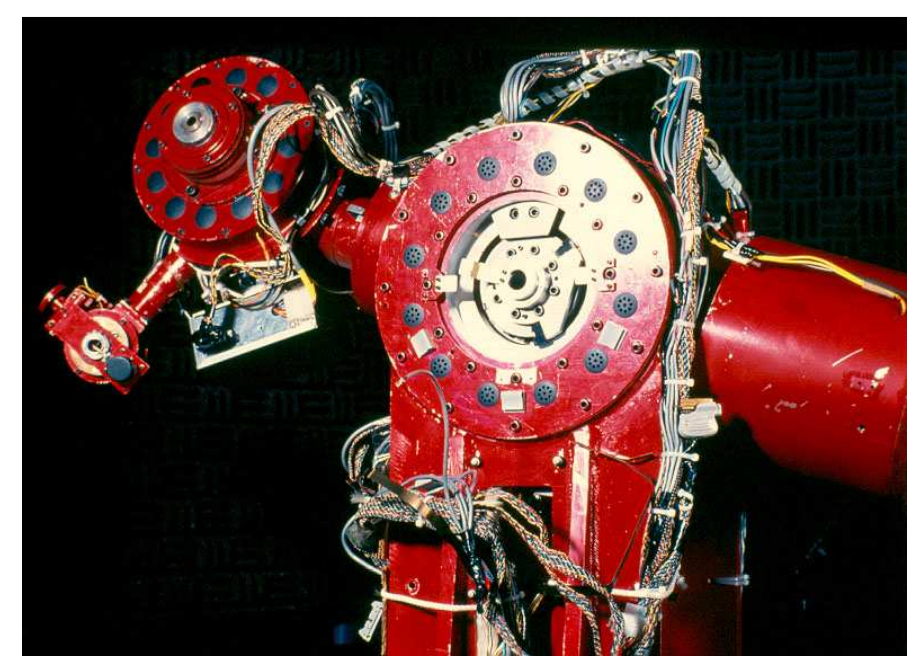

Fig. 8 The CMU Direct Drive Arm (from [21]) 
In the 1980's, industrial robotics enjoyed both an enormous interest and a considerable increase in the number of installations. Robotics was identified, by industrialists, politicians, researchers and journalists, as a crucial area for industrial development and a terrific tool to achieve increased competitiveness. Moreover, in the second half of the 1980's decade, advanced sensors (such as laser scanners, cameras and force sensors) began to be employed in robotics, allowing robots to perform increasingly complex tasks.

\section{From serial to parallel kinematics: the Delta robot}

Another important stream in the history of industrial robots is connected with the search for high-speed operation. To this respect, a change in the kinematic configuration led to promising results: namely, parallel kinematic machines (called "parallel robots") could be conceived. With respect to the "traditional" serial robots, this kind of manipulators feature more lightweight structures, thus can reach higher operational speeds, at the cost of a reduction of the workspace volumes. Parallel robots are therefore particularly suited for high-speed tasks, where precision is also required (for example, picking or machining operations). The most important example of parallel robot is definitely the Delta robot, developed by the Swiss company Demaureux, which in 1992 used this kind of robot in an installation named "Presto" ("soon" in Italian), aimed at performing pick-and-place tasks.

The Delta robot was based on the idea by Reymond Clavel, Professor at the EPFL (Ecole Polytechnique Fédérale de Lausanne), who in his PhD thesis (1981) designed a parallel robot, built with parallelograms, having three translational and one rotational degrees of freedom [22] (Fig. 9).

The Delta robot had a huge success, due to its capability to perform high-speed operations. Many versions of Delta robot were designed and built in the following years, as for instance the IRB 340 Flexpicker manufactured by ABB (1999). 


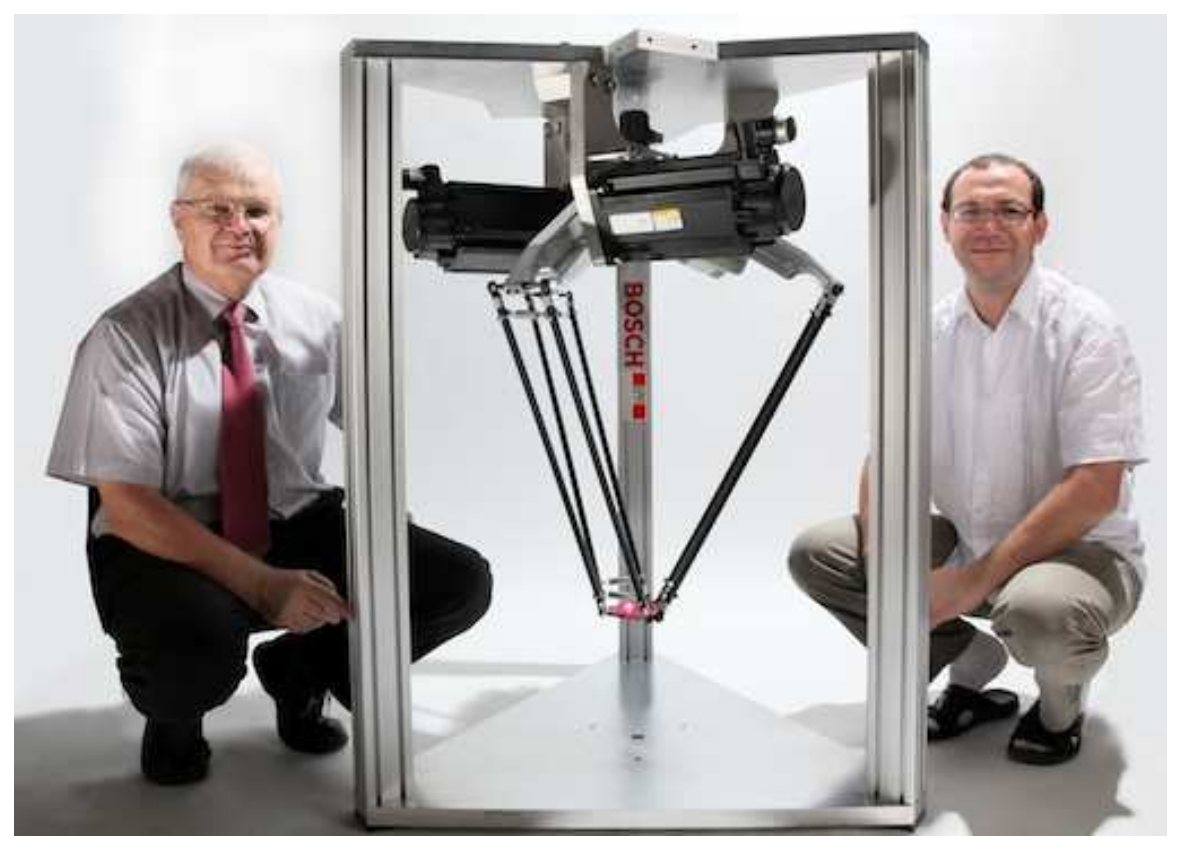

Fig. 9 Reymond Clavel (left) with a Delta robot

\section{Conclusions}

In this paper, the first decades of history of the industrial robotics are presented, starting from the ideas of Devol and Engelberger, that led to the birth of Unimate, the first industrial robot, up to the appearance of the Delta robot, which was the first of a series of high-speed robots with parallel kinematics. In this historical sketch, both technical and economic factors have been taken into account.

The evolution of industrial Robotics is still going on in the current day: it can be said that new ideas and the technological progress gave a new life to industrial robotics, which only few years ago seemed to have reached its complete maturity. New human-robot interfaces, novel programming techniques based on artificial intelligence and "deep learning", as well as an extraordinary development in the sensors technology as well as in the wireless technology gave industrial robotics a new youth, revolutionizing the traditional concepts of factory automation. 


\section{References}

1. Ceccarelli M., "A Historical Perspective of Robotics Toward the Future", Fuji International Journal of Robotics and Mechatronics, 2001, Vol.13, No.3, pp.299-313.

2. Ceccarelli M., Fundamentals of Mechanics of Robotic Manipulation, Kluwer/Springer,Dordrecht, 2004.(ISBN 1-4020-1810-X)

3. Gasparetto, A., Robots in History: Legends and Prototypes from Ancient Times to the Industrial Revolution. In: Explorations in the History of Machines and Mechanisms, Vol. 32 of the series History of Mechanism and Machine Science, pp. 39-49, 2016

4. Zamalloa, I., Kojcev, R., Hernandez, A., Muguruza, I., Usategui, L., Bilbao, A. and Mayoral, V., Dissecting Robotics - historical overview and future perspectives, preprint available on arXiv.org (arXiv:1704.08617), April 2017

5. Wallén, J., The history of the industrial robot, Technical report from Automatic Control at Linköpings Universitet, 2008. Available at: http://www.control.isy.liu.se/publications.

6. Lagerberg T., Jonson, J., Une bio du robot. Petite histoire de la robotique industrielle. ABB Review 3/16, 2016. Available at: http://new.abb.com/about/technology/abb-review.

7. Sicliano, B., Khatib, O., (Eds.), Springer Handbook of Robotics, Springer-Verlag Berlin Heidelberg 2008.

8. Mathia, K., Robotics for Electronics Manufacturing. Principles and Applications in Cleanroom Automation. Cambridge University Press, 2010.

9. Westerlund, L. The Extended Arm of Man - A History of the Industrial Robot. Informationsförlaget, Stockholm, Sweden, 2000

10. https://patents.google.com/patent/US2820187A/en

11. https://patents.google.com/patent/US2632574A/en

12. https://patents.google.com/patent/US2988237

13. Malone, B., George Devol: a Life Devoted to Invention, and Robots. IEEE Spectrum Magazine, Sept. $26^{\text {th }}, 2011$. Available at: https://spectrum.ieee.org/automaton/robotics/industrialrobots/george-devol-a-life-devoted-to-invention-and-robots

14. https://ifr.org/robot-history

15. Scheinman, V., Design of a Computer Controlled Manipulator, PhD thesis, Stanford University. Available at http://www.dtic.mil/docs/citations/AD0708069.

16. http://www.stanford.edu

17. Karlsson, J.M., A Decade of Robotics; Analysis of the Diffusion of Industrial Robots in the 1980s by Countries, Application Areas, Industrial Branches and Types of Robots. Mekanförbundets Förlag, Stockholm, Sweden, 1991.

18. https://anil89cs.wordpress.com/2009/07/26/cincinnati-milacron-t3-robot-arm

19. http://www.interactivearchitecture.org/performing-scara-robots.html

20. Asada, H. and Kanade, T., Design of Direct-Drive Mechanical Arms, J. Vib., Acoust., Stress, and Reliab 105(3), 312-316 (Jul 01, 1983)

21. http://www.cs.cmu.edu/

22. Clavel, R., "Conception d'un robot parallèle rapide à 4 degrés de liberté," $\mathrm{Ph} . \mathrm{D}$. Thesis, EPFL, Lausanne, Switzerland, 1991. 